\title{
A Comparative Study of the Physico-Chemical Characteristics of the Ready-to Eat Coconut Based Snack
}

Sivasakthi $\mathbf{M}^{*}$ and Sangeetha $\mathbf{N}$

Department of Food Science and Technology, Pondicherry University, Puducherry-605014, Tamil Nadu, India

\begin{abstract}
Coconut slices (thickness $0.8 \pm 0.1 \mathrm{~mm}$ ) were osmotically dehydrated ( $0 \mathrm{~min}$ to $720 \mathrm{~min}$ ) using filtrates of functional ingredients such as beet root, carrot, ginger and mint as impregnating solutions. During the osmotic process, the diffusion of minerals, organic acids, phenolics and vitamins between coconut slices and osmotic medium might have contributed various physico-chemical changes in acidity, TSS (Total soluble solids) of the osmotic medium and rehydration characteristics of the snack. The kinetics of osmotic dehydration process revealed that significant changes in mass transfer parameters WR (Weight reduction), SG (Solid gain) and WL (Water loss) observed during 450th minutes of the process, irrespective of the functional filtrates and dehydration methods used (hot-air oven at temperature $45-60^{\circ} \mathrm{C}$ for about $6-7$ hours and freeze drying at temperature $\left(-40\right.$ to $\left.30^{\circ} \mathrm{C}\right)$ for a duration of 14-16 hours). Texture analysis revealed that osmotic dehydration induced modifications in cell structure of the coconut based snack with respect to the drying methods and the use of sugar as osmotic infusions.
\end{abstract}

Keywords: Osmotic dehydration; Coconut slices; Functional ingredients; Physico-chemical; Drying methods

\section{Introduction}

The roots carrots (Daucus carota) and beet roots (Beta vulgaris), the spices like mint (Mentha piperita) and ginger (Zingiber officinale) always contributed an imperative role in the social, economic lives and food habits all over the nation. In India, the production of beet roots was estimated about $1.16 \%$ to $33.42 \%$ in the year 2011-12 [1]. Carrot production in India was estimated about 1.15 million tonnes in the year 2012-13 [1]. Carrots and beet roots generally contains considerable amount of natural sugars, phenolic compounds such as carotenoids, anthocyanins, flavonoids, betacyanin and betaxanthin, the natural antioxidants essential for potential health benefits. The spices mint and ginger are consumed worldwide. In India the production of ginger was $33 \%$ of the global production and 12,000 tonnes of mint oil was produced from $75 \%$ of menthol mint estimated in the year 2001 [2]. Mint and ginger are well known for their pungency principles menthol, menthone, terpenoids, curcumin, shogaols, gingerols and antioxidant vitamins and minerals which play vital task in therapeutic applications.

Coconuts are grown widely in subtropical and tropical regions and considered as a major ingredient in daily cuisines. Coconuts are rich in inorganic ions like potassium, sodium, phosphorus and calcium etc, which helps in blood coagulation. He also reported that coconuts composed of fatty acids like caprylic acid (8\%), capric acid (7\%), lauric acid (49\%), myristic acid (18\%), palmitic acid (8\%), stearic acid (2\%), oleic acid (6\%), linoleic acid (2\%) and profuse nature of presence of medium chain saturated fatty acids (MCFAs) which enables them to be absorbed directly from the intestines and straightly sent to the liver, which then metabolized and energy is produced [3].

Coconuts are used as ready to eat food products in confectionary food items and ice-creams in the form of pie filling, fruit ice cream with the assistance of dehydration techniques like osmotic dehydration (OD), Kabara [4] and further drying proceeded such as air drying, hot air oven drying, freeze drying and microwave drying etc., to get dried fruits, snacks and other products with extended keeping quality. The consumers prefer dried food products in terms of convenience, good health and pleasure.

Osmotic dehydration is a process in which partial removal of water from tissues of plant by dipping in hypotonic solutions. During the osmotic dehydration process, two major counter current passes due to water and the activity of the solute: the diffusion of water from food to the osmotic medium and solute from solution to the food. The mass transfer mechanism is mainly attributed to the activity of water and solute across the membrane of cell enables equilibrium between the solute and water [5]. Conventionally OD process has been carried out in atmospheric pressure. Now-a-days OD plans a significant role in industrial sector for pre-drying purposes to achieve better textural characteristics with associated changes in color, Total soluble solids (TSS). The color changes in dried food products could be in reliant with the presence of poly phenols and other sugars. The mass kinetics are generally proceeds in the DIS (Dehydration Impregnation Soaking) phenomenon which influences variables like temperature, concentration of osmotic medium, sample shape, size and agitation [6].

This paper documents the development of ready-to eat coconut based snack and the changes occurred during the process of OD of the coconut slices like TSS, sugar-acid ratio, acidity and mass transfer kinetics WR, SG and WL and rehydration characteristics using filtrates of functional ingredients such as Beta vulgaris, Daucus carota, Zingiber officinale and Mentha piperita as osmotic medium as a pre-treatment followed by assisted drying methods namely hot air oven drying and freeze drying to obtain healthy snack enriched with functional properties.

\section{Materials and Methods}

\section{Solvents and reagents}

Gallic acid, phosphotungsto molybdic acid, folin- Denis reagent (FD) and $\mathrm{Na}_{2} \mathrm{CO}_{3}$, folin-ciocalteu's Reagent, monobasic potassium

*Corresonding author: Sivasakthi $\mathrm{M}$, Department of Food Science and Technology, Pondicherry University, Puducherry-605014, Tamil Nadu, India, Tel: 91 9488260590; E-mail: sivasakthiphd2015@gmail.com

Received June 11, 2015; Accepted July 11, 2015; Published July 18, 2015

Citation: Sivasakthi M, Sangeetha N (2015) A Comparative Study of the PhysicoChemical Characteristics of the Ready-to Eat Coconut Based Snack. J Food Process Technol 6: 489. doi:10.4172/2157-7110.1000489

Copyright: (c) 2015 Sivasakthi M, et al. This is an open-access article distributed under the terms of the Creative Commons Attribution License, which permits unrestricted use, distribution, and reproduction in any medium, provided the original author and source are credited. 
phosphate, magnesium carbonate, sodium sulphate, acetone, hydrochloric acid, acetate buffer, 2,4,6-tripyridyl-s-triazine), ferric chloride, were purchased from Scientific suppliers (Pondicherry, India). Chromatographic grade methanol, ethanol, acetonitrile, glacial acetic acid, phosphoric acid, formic acid, 5\% tetrahydrofuran, were purchased from Merck (Mumbai, India). Standards: All standards were of analytical grade. Quercetin RS, kaempferol, myricetin, apigenin, luteolin, hesperidin and isorhamnetin were obtained as described by Crozier et al. [7].

\section{Selection and pre-processing of raw materials}

Matured, fresh and good quality coconuts were procured from the shop Pazhamudir Nilayam, Pondicherry to carry out research on osmotic dehydration. The steps included in preliminary processing of coconuts such as selection of coconuts ( 10-12 months old), husk removal, breaking coconuts into two halves, endosperm separation from shell and testa removal with sharp knife. The processed coconuts were further standardized to get optimum thickness using the slicers to conduct experiments.

Using screw gauge the pre-processed coconuts were sliced ranged from thickness $0.6 \mathrm{~mm}$ to $1.0 \mathrm{~mm}$ to get optimum thickness. To avoid microbial contamination, the coconut slices were kept immersed in water in a vessel before starting the experimental analysis. Steam blanching of the coconut slices was done at the temperature 80 to $90^{\circ} \mathrm{C}$ for 5 minutes to prevent enzymatic actions. Osmotic dehydration of the pre-processed slices was performed using sugar as the osmotic agent. Since it is available everywhere, easy to procure, low cost, possessing good diffusion and mass transfer properties according to Lerici et al. [8].

Sugar was used as one of the main ingredient in osmotic medium along with functional filtrates namely Daucus carota, Beta vulgaris, Mentha piperita and Zingiber officinale were procured from Pazhamudir Nilayam, Puducherry and the process of osmotic dehydration was carried out. The functional ingredients such as beet root, carrot, ginger and mint were pre-processed using simple steps like washing, peeling, grating, grinding into fine paste and filtered to get filtrates using 0.08 $\mathrm{mm}$ sieve. The functional filtrates were taken in the range from every $5 \%$ addition up to $100 \%$ and infused with sugar as the main ingredient in osmotic medium (100\%). For standardization purpose the coconut slices, sugar and filtrates of functional ingredients were taken in three ratios like $1: 1: 1,1: 2: 2$ and 1:3:3.

\section{Process involved in the formulation of ready-to-eat coconut based snack}

The process of osmotic dehydration was performed with or without the infusion of functional filtrates for duration of $0 \mathrm{~min}$ to $720 \mathrm{~min}$. The finalization of duration of the osmotic process was based on the physico-chemical characteristics of the coconut samples like maximum decline in brix, weight of the osmo dehydrated coconut slices and the extent of impregnation of functional properties.

Hot air drying and freeze-drying were adopted in the present study. The coconut samples were dehydrated in hot air oven dryer by allowing hot air which flushed inside the chamber and the food gets exposed to hot air, the desired moisture content achieved due to removal of moisture up to $2-3 \%$. The desired moisture content was attained with standardized temperature $45-50^{\circ} \mathrm{C}$ and time 6-7 hours which was dependent on the nature of the product, whereas most of the fruits and vegetables are dehydrated in the temperature range $50-60^{\circ} \mathrm{C}$ to get dried foods without much degradation reactions [9]. The coconut samples were dehydrated using freeze dryer (Model: Del Vac) by spreading the samples uniformly in the trays and kept inside the chamber where all the valves are closed and checked whether the instrument working under vacuum condition. The low temperature $-40^{\circ} \mathrm{C}$ to $30^{\circ} \mathrm{C}$ was applied over a period of time 14-16 hours, which found to preserve the color and texture of the samples through thermostat adjustment. The instrument worked under an automatic mode with respect to vacuum and temperature. As soon as the drying process is completed, the instrument is switched off and a slow release of vacuum was ensured, finally the samples were collected. The dehydrated coconut based snacks developed using hot air oven and freeze drying methods were packed in aluminium foil laminated LDPE pouches with $100 \%$ infusion of nitrogen gas and kept for storage at temperature $35^{\circ} \mathrm{C}$ prior to analytical determinations.

\section{Finalized process parameters}

The process parameters were represented in the ratio 1:2:2 after several permutations and combinations from the above methodology. The ratio 1:2:2 represents thickness of coconut slices, sweetness of sugar and concentration of various filtrates obtained from the functional ingredients, which were essential further processing. The infusion of sugar and impregnation functional filtrates at $100 \%$ concentration contributed the coconut based snack with most acceptable texture, taste, sweetness and crispiness; hence finally this proportion was selected. However the control snack represents the process of osmotic dehydration of the coconut slices in which the filtrates of functional ingredients were not impregnated.

\section{Quality analysis of the ready-to-eat coconut based snack}

The physico-chemical characteristics of the coconut based snack were analyzed after the finalization of various process parameters as per standard methods and protocols. All analytical determinations were carried out in triplicate Values were represented as mean \pm standard deviation.

Effect of drying methods and impregnation of filtrate of functional ingredients on the physico-chemical characteristics of the ready-to-eat coconut based snack and the osmotic solution

Osmotic process is influenced by the $\mathrm{pH}$ of the osmotic solution. Whereas gradual removal of water from the food materials subjected to osmosis depends mainly on acidity of the osmotic solution which has impact on textural properties of fruits and vegetables.

\section{Physico-chemical properties of the osmotic solution:}

Acidity (\%): The physico-chemical property acidity of the osmotic solution was analyzed by titrimetric method [10], where $0.1 \mathrm{~N}$ of sodium hydroxide is titrated against $0.1 \mathrm{~N}$ oxalic acid using phenolphthalein as an indicator.

Total soluble solids (TSS) ( $\left.{ }^{\circ} \mathbf{B x}\right)$ : About $5 \mathrm{~g}$ dried samples were extracted with $250 \mathrm{ml}$ of acetone for $24 \mathrm{hr}$. For sterol analysis, acetone extracts were used frequently. Gas chromatography was used to separate individual sterols by $1.80-\mathrm{m}$ column, $6 \mathrm{~mm}$ id., packed with $5 \mathrm{z} \mathrm{OV}-101$ on Anakrom ABS 80- to 90-mesh. The temperature of the column was $250^{\circ} \mathrm{C}$ and the temperature of flash heater was kept $50^{\circ} \mathrm{C}$ above that of the column. The temperature of flame ionization detector was $275^{\circ} \mathrm{C}$. The carrier gas was Helium at a flow rate of $100 \mathrm{ml} / \mathrm{min}$ [11].

Sugar-acid ratio: Sugar acid ratio of the osmotic solutions were determined using the formula,

TSS $/$ Acid ratio $=\mathrm{TSS} / \%$ acidity $[12]$. 
Physico-chemical properties of the ready-to-eat coconut based snack: The mass fluxes occurred through osmotic dehydration not only cause changes in the structure of tissues due to cellular alterations by immersion of foods in concentrated solutions, promotes water loss, deformation and breakage of cellular components associated with gasliquid exchanges, but also result in conformity with the product texture and appearance [13].

Texture analysis-crispiness $(\mathbf{N})$ : Texture analysis of the readyto-eat coconut based snack was performed with a $5 \mathrm{~mm}$ HDP-CFS cylindrical ball probe by Texture Analyzer (Model No. 5197, stable Micro Systems HD Plus, Gold alming, Surrey, GU71YL, UK). Each slice of the coconut snack was placed on the heavy duty platform and the test speed was set to $1 \mathrm{~mm} / \mathrm{sec}$ and the probe compressed $50 \%$ of the snack to measure the hardness. Recording of maximum force is calculated as the hardness of the slices. Maximum breaking force $(\mathrm{N})$ and deformation were measured from the force-deformation curve.

Analysis of color using Hunter lab color flex: Color of the readyto-eat coconut based snack including 5 or 6 slices from each treatment were selected to determine using the Hunter's Lab Colorimeter (Model: CX2748, Easy Match QC, Software Version 4.0, Hunter Lab, USA) with spectral reflectance. The Hunter Labs color space is a 3-dimensional rectangular color space based on the opponent-colors theory. The color determinations were reported as $\mathrm{L}^{\star}, \mathrm{a}^{\star}, \mathrm{b}^{\star}$, whereas (lightness) axis - 0 is black, 100 is white, $\mathrm{a}^{\star}$ (redness-greenness) axis -positive values are red; negative values are green and 0 is neutral, $b^{*}$ (yellowness-blueness) - positive values are yellow; negative values are blue and 0 is neutral values and $\Delta \mathrm{E}$ indicates the overall average color according to Olajide [14].

The hue angles were calculated as the arctangent of $b^{*} / a^{*}$ expressed as degrees and the chroma values were also calculated as the square root of the sum of the squared values of both CIE $a^{*}$ and CIE $b^{*}$. The chroma and Hue angle were calculated by the formulas given below.

$$
\begin{aligned}
& \text { Chroma }=\sqrt{a^{2}+b^{2}} \\
& \text { Hue angle }=\tan ^{-1}(\mathrm{~b} / \mathrm{a})
\end{aligned}
$$

\section{Mass transfer kinetics}

The process of osmotic dehydration generally results in exchange of water from food to the solution and from the solution to the food and also migration of natural solutes like minerals, vitamins, organic acids, sugars, reducing sugars, some flavor compounds, volatiles, etc., from the food materials to the solution which affects nutritional and sensory quality of the foods. Osmotic dehydration reduces the water activity in foods by effective moisture removal process due to driving force exerted by the osmotic agent in the solution; thereby microbial entry is prevented [15]. Thus the mass transfers help in overall yield and quality of the dehydrated food products. Due to the semi permeable nature of the plant tissue, the flux of water removal is greater owing to smaller molecular size of water molecules. This paved a way for the decrement in water content in foods with respect to time till equilibrium gradient is attained. Hence weight of the food materials decreased corresponds to water activity. Rastogi and Raghavararo [16] examined that about 50\% of reduction in fresh weight of vegetables and fruits obtained through osmotic dehydration with strengthened structure and enable easy transportation, occupy less storage space.

The coconut slices of $0.8 \pm 0.1 \mathrm{~mm}$ were removed from the immersion solution at selected time intervals of $5,10,15,20,25$ and 30 min and quickly rinsed (with distilled water) during preliminary trial processes, later on the time increased up to 720 minutes and readings taken at every 90 minutes interval. The excess of solution at the surface of the slices was removed with absorbent paper.

\section{Weight reduction (\%)}

The coconut slices were weighed before and after osmotic dehydration to calculate the percentage of weight reduction (WR). The final weight of food samples is affected by the overall exchange mechanism between the solid and liquid of the sample. The moisture content was determined to calculate water loss (WL) and solid gain (SG) based on the following equations [17].

\section{$\mathrm{WR}(\%)=\left(\mathrm{W}_{\mathrm{i}}-\mathrm{W}_{\mathrm{f}}\right) / \mathrm{W}_{\mathrm{i}}{ }^{*} 100$}

Where, $\mathrm{W}_{\mathrm{i}}$ is the initial mass of the sample $(\mathrm{g}), \mathrm{W}_{\mathrm{f}}$ is the final mass of the sample (g).

\section{Solids gain (\%)}

Solids gain represents the amount of solids gained from the osmotic medium that the amount of sugar uptake by the slices from the osmotic solution. During osmotic dehydration, water flows from the food materials into the concentrated osmotic medium, and solute transferred from the osmotic medium into the food material [18].

$$
\mathrm{SG}(\%)=\left(\mathrm{W}_{\mathrm{sf}}-\mathrm{W}_{\mathrm{si}} / \mathrm{W}_{\mathrm{i}}\right){ }^{\star} 100
$$

Where, $\mathrm{W}_{\mathrm{si}}$ is the initial total solids content in the sample $(\mathrm{g}), \mathrm{W}_{\mathrm{sf}}$ is the final total solids content in the sample (g).

\section{Water loss (\%)}

Water loss represents the total amount of weight reduction as well as the solids gain taking place when the osmotic dehydration is taking place. WL is the net loss of weight of the foods on initial weight basis occurred during the process of osmotic dehydration [15].

$$
\mathrm{WL}=\mathrm{SG}+\mathrm{WR}
$$

\section{Rehydration characteristics}

Rehydration is defined as a complex procedure affected by a number of factors such as chemical composition of the product, drying techniques and conditions, immersion medium composition, temperature etc., which measures the quality characteristics of the product. Rehydration depends on the nature and degree of pretreatment of the foods [19-21].

Best quality dehydrated snack prepared from the above treatments samples were used for studying the rehydration characteristics with four replications. Rehydration of the coconut snack slices is ensured by soaking $10 \mathrm{~g}$ of the samples in a beaker containing boiled distilled water $\left(50^{\circ} \mathrm{C}\right)$ of five times the weight of the dehydrated snack according to the procedure of Lewicki [22] with slight modifications. At time intervals of 5,10,15,20,25 and 30 minutes, the rehydrated slices were taken out from the beaker. After removing the adhering water by using the blotting paper, weight of the slices were noted and then placed in the water for further rehydration. The rehydration character of the snack is better than that of the desiccated coconut powder. The rehydration parameters were determined according to Lewicki [22] as rehydration ratio and coefficient of rehydration.

Rehydration ratio $(\mathrm{RR})=\mathrm{WR} / \mathrm{WD}$, Coefficient of rehydration $(\mathrm{CR})=\mathrm{WR} / \mathrm{Wo}$

Where $\mathrm{WR}=$ drained weight of rehydrated sample $(\mathrm{g}), \mathrm{WD}=$ weight of dehydrated sample $(\mathrm{g})$, Wo = weight of sample before dehydration $(\mathrm{g})$.

\section{Statistical interpretation of the data}

The analyses on sensory, physical, chemical, functional, 
phytochemical and shelf-life characteristics were done using triplicate samples. The data on experimental results were subjected to Analysis of Variance (ANOVA) and differences between means were assessed by LSD and independent sample ' $\mathrm{t}$ ' test using the statistical package SPSS (18 version) to compare the means to determine the most acceptable treatment $(p \leq 0.05)$.

\section{Results and Discussion}

\section{Physico-chemical characteristics of the osmotic solution}

Acidity (\%) value of the osmotic solutions: Figure 1 explains the percent acidity value of the osmotic solutions. The percentage acidity values of the control solution were 0.03 during $90 \mathrm{~min}$ and 0.2 in the $450 \mathrm{~min}$ beyond which it remained stable. The acidity level of the filtrate of functional ingredients ranged from 0.03 to $0.06\left(90^{\text {th }} \mathrm{min}\right)$ to 0.22 to $0.30\left(450^{\text {th }} \mathrm{min}\right)$ beyond which there was no change in the acidity levels. The percent acidity range observed at $90^{\text {th }}$ min reveals the presence of minimum to maximum percentage acidity in the impregnated solutions D (Beta vulgaris) and A (Mentha piperita). Whereas the percent acidity value of filtrate $B$ ranged from 0.054 to 0.27 at $90^{\text {th }}$ and $450^{\text {th }}$ min respectively, whilst filtrate $\mathrm{C}$ ranged from 0.059 to 0.25 at $90^{\text {th }} \mathrm{min}$ and $450^{\text {th }}$ min which was observed as an intermediate acidity percent value between solutions $\mathrm{D}$ and $\mathrm{A}$.

The acidity levels of the control solution were lesser than the functional filtrate solutions which could be due to the diffusion of organic acids from the sample into the solution. The outcome of the present study was in par with the finding of Dahiya and Dhawan [23] who reported that osmotic dehydrated aonlas found to contain lower acidity values, whereas osmotic solution contains higher acidity values. The analysis of variance of the results of the present study indicated that the impregnation of filtrates of functional ingredients through osmotic dehydration had a significant $(p \leq 0.05)$ effect on acidity towards better product development and moreover acidity factor acts as an important attribute for enrichment of flavor as well [24].

Total Soluble Solids $\left({ }^{\circ} \mathrm{Bx}\right)$ of the osmotic solutions: Figure 2 reveals the TSS of the osmotic solutions. The TSS $\left({ }^{\circ} \mathrm{Bx}\right)$ values were found to decrease as the time increases during osmotic dehydration. The descending tendency of the TSS in the osmotic solutions observed in the present study was in par with the findings of Spiess et al. [25] who noted significant changes such as transfer of water from grape fruit to the solution and solute uptake by the grape fruit.

The TSS values of the control osmotic solution were comparatively lesser than all functional filtrates due to the natural presence of sugars in the filtrate. The TSS value of control solution ranged from $52.11\left(90^{\text {th }}\right.$ $\mathrm{min})$ to 45.41 ( $450^{\text {th }} \mathrm{min}$ ), whereas among functional filtrates, the range was slightly higher especially in infusion of Daucus carota $\left(55.00-90^{\text {th }}\right.$ min to $49.2-450^{\text {th }} \mathrm{min}$ ) and Beta vulgaris infusion $\left(53.40-90^{\text {th }}\right.$ min to $49.00-450^{\text {th }} \mathrm{min}$ ). The changes in TSS of Mentha piperita and Zingiber officinale filtrate infusions ranged from 51.50 to 45.41 and 52.68 to 46.40 which was observed for duration from every $90 \mathrm{~min}$ to $450 \mathrm{~min}$ and showed significant difference at $p \leq 0.05$, beyond which no change was observed. Thus analysis of variance applied between the sugar infused osmotic solutions either with or without the impregnation of filtrates of functional ingredients had significant effect on TSS of readyto-eat coconut based snack. During osmotic dehydration, removal of water enhanced in the coconut slices and remarkable increment in TSS was noted. The outcome was consistent with the findings of RaoultWack [12] who has determined that utilization of hypertonic solutions result in $70 \%$ of removal of water without any heat applications.
Azuara [26] reported that better weight reduction, solid gain and water loss was obtained by the usage of concentrated sugar solutions in the apple disks. The change in TSS might be due to the migration of osmotic solution from higher sugar concentration to lower sugar concentration and uptake of solutes by the samples from the solution. The finding of the present study was similar to the result of RaoultWack et al. Delgado and Rubiolo [27] and Fathi et al. [28], where significant changes in balance of concentration between solid foods and solution subjected to osmotic dehydration, especially in case of pomegranate seeds was observed.

Sugar acid ratio: The sugar acid ratio of the osmotic solution is discussed in Figure 3. The sugar acid ratio of all the osmotic solutions was found to decrease with increase in time corresponding to the increased acidity and decreased TSS levels. However the SAR of the control solution was significantly greater $(p \leq 0.05)$ than all samples impregnated with filtrate of functional ingredients. The sugar acid ratio of the control solution ranged from 2605.50 to 225.55 and that of sample D impregnated with Beta vulgaris was highest ranging from 2341.00 to 215.86, followed by Beta vulgaris impregnated osmotic solution D. The succeeding order of sugar acid ratio was found in impregnated osmotic solutions C (Daucus carota), B (Zingiber oficinale) and A (Mentha piperita) possessing initial and final values in the range of 2052.00 to $193.70,1173.00$ to 173.78 and 914.00 to 158.22 respectively, which represents the prolific presence of sugars and organic acids in the functional ingredients. Thus the results of variance of analysis showed that the osmotic solutions either with or without impregnation of functional ingredients had a significant $(p \leq 0.05)$ effect on sugar acid ratio of ready-to-eat coconut based snack. This parameter plays a vital role in assessing the overall quality of dehydrated products with respect to flavor enrichment.

\section{Physico-chemical properties of the ready-to-eat coconut based snack}

Texture analysis-crispiness $(\mathrm{N})$ of the ready-to-eat coconut based snack: Figure 4 depicts the textural characteristics of the ready-to-eat

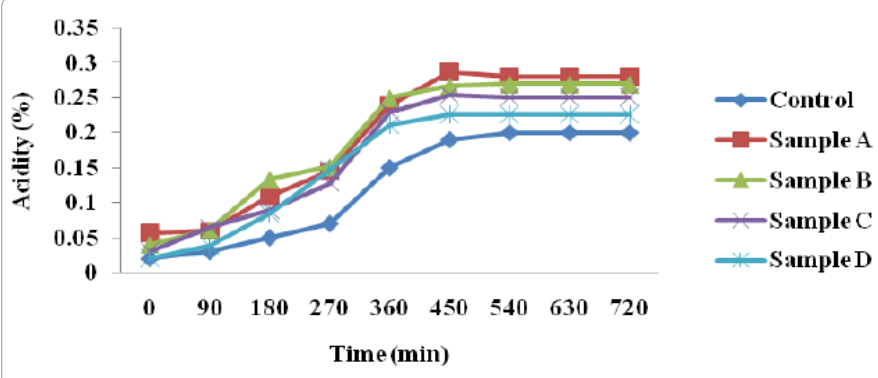

Figure 1: Acidity (\%) of the osmotic solutions.

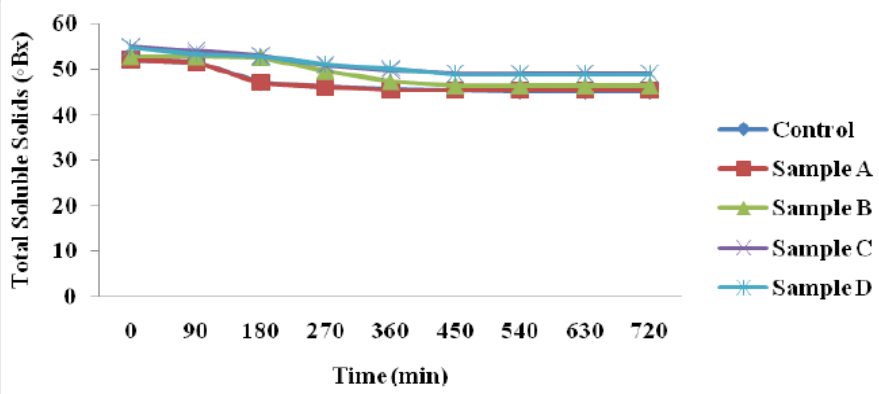

Figure 2: Total soluble solids $\left({ }^{\circ} \mathrm{Bx}\right)$ of the osmotic solutions. 


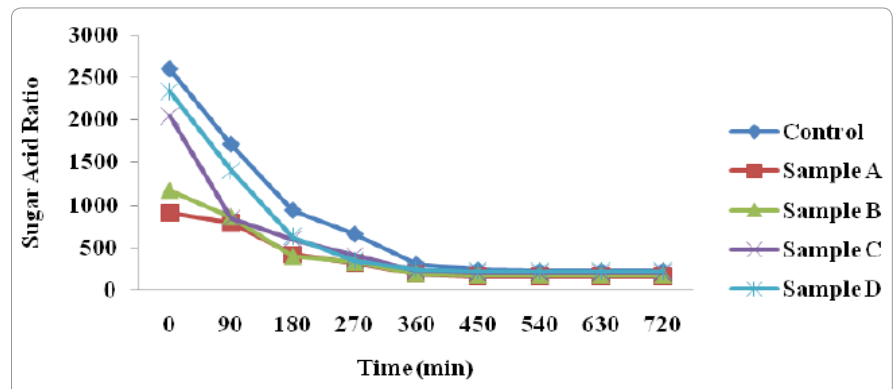

Figure 3: Sugar acid ratio of the osmotic solution.

coconut based snack. Texture analysis of the samples was performed with a HDP-CFS cylindrical ball probe using Texture Analyzer. Maximum breaking force $(\mathrm{N})$ and deformation were measured from the force-deformation curve. Almost the breaking force for all the samples required around 5.7 to $5.9 \mathrm{~N}$, hence there was no significant difference observed ( $\mathrm{p} \geq 0.05)$. The optimum force required to break the snack was dependent on the hardness of the tissue and cell wall matrices. The concept was made in agreement with Lewicki [22] who stated that textural behavior is mainly related to the structural and biophysical properties of foods. Also the increase in time and concentration of solutes affect the texture of the osmotic dehydrated foods. Sucrose present in fruits and vegetables acts as an important factor influencing the texture of foods.

Color analysis of the ready-to-eat coconut based snack: Table 1 reveals the color characteristics of ready-to-eat coconut based snack. On analyzing the color parameters, the control samples possessed significantly lesser $(p \leq 0.05)$ chroma values ( $T_{1}$ Control-4.64, $\mathrm{T}_{2}$ Control-4.94) than samples impregnated with functional filtrates with respect to the changes in the intensity of hue values. Irrespective of the drying method adopted, higher chroma values was observed in the impregnated samples $\mathrm{D}\left(\mathrm{T}_{1} \mathrm{D}-17.40, \mathrm{~T}_{2} \mathrm{D}-17.14\right)$ and $\mathrm{C}\left(\mathrm{T}_{1} \mathrm{C}-13.9\right.$, $\mathrm{T}_{2} \mathrm{C}$-13.94) which could be due to the presence of colored pigments with grater intensity when compared with sample $\mathrm{A}\left(\mathrm{T}_{1} \mathrm{~A}-10.50, \mathrm{~T}_{2} \mathrm{~A}-\right.$ 9.70) and sample $B\left(T_{1} B-6.65, T_{2} B-5.87\right)$.

The lightness of the samples exposed to freeze drying was found to contain higher values due to the retention of nutrients without much degradation of pigments as drying was carried out at low temperature. Moreover the increased lightness values represents the preservation of pigments and nutrients without enzymatic deterioration in freeze dried samples than hot air oven dried which is related to the outcome of Krokida and Maroulis [29] who stated that the preservation of color of foods might be observed by its constant lightness L parameter thereby in chroma values. The finding of the present study was similar to the result of Larrauri et al. [30] who reported that $L^{*}$ values of the hot-air dried samples were significantly lower than the freeze-dried samples of the red grape pomace peels.

However the hot air oven dried samples A and B subjected to temperature $45^{\circ} \mathrm{C} \pm 10^{\circ} \mathrm{C}$ resulted in decrement of degradation of pigments revealed more or less similar $\mathrm{a}^{\star}$ values when compared with freeze dried samples with slight significant difference at $p \leq 0.05$. The $a^{*}$ values of the hot air oven dried samples $C$ and $D$ found to possess slightly higher values than freeze dried samples due to enzymatic degradation of pigments which was in agreement with the finding of Krokida et al. [31] who reported that the $\mathrm{a}^{*}$ chroma value of air dried samples increase significantly during air drying. The increase of the a-value denotes a more red color, which is indicative of the browning reaction. A small increment in $\mathrm{b}^{\star}$ values (yellowness) was observed in all functionally infused coconut samples of both drying methods than control samples corresponding to the increase in $\mathrm{a}^{\star}$ values which was consistent with the result of Krokida et al. [29] who indicated that there was an increment in the $b^{*}$ values (yellowness) which was observed in untreated samples of banana whereas slower increase in $b^{*}$ value was observed in osmotic treated samples.

The chroma value of the hot air dried and freeze dried control samples were found to hold slightly decreased values than functionally infused samples, which represents the nature of pigments present in the functional ingredients. Nevertheless the chroma value of the coconut samples of both the drying methods retained almost similar values with slight significant difference at $p \leq 0.05$. However the chroma and total color difference of the freeze dried infused samples found to possess slightly lesser values than hot air dried samples indicating meager degradation of pigments. The increment in the total color difference was measured with reference to the 3 co-ordinates $\mathrm{L}^{*}, \mathrm{a}^{*}$ and $\mathrm{b}^{*}$ where lower lightness and higher $\mathrm{a}^{*}$ and $\mathrm{b}^{*}$ values were observed according to the concept of Cortes et al. [32].

The hue angle value of sample $\mathrm{D}$ of both the drying methods was found lowest than standard $90^{\circ}$ hue angle which represents the presence of orange-red color, followed by hot air dried sample $\mathrm{C}$ with hue angle of 83.34, freeze dried sample $\mathrm{C}$ of hue angle -85.39 , followed by hue angles of sample $T_{1} B$ and $T_{2} B(-82.83$ and -80.52$)$, finally control snack and sample $T_{1} A$ and $T_{2} A$ possessing hue angle values nearer to $90^{\circ}$ which specifies the yellowness and greenness of the samples. The increase in chroma and total color difference values represents the extent of change in color during osmotic dehydration and also reduction of pigments occurred during drying process which could be related to the concept of Larrauri et al. [30].

Mass transfer kinetics: Bekele and Ramaswamy [33] reported that osmotic dehydration (OD) process involves soaking of foods in hypertonic solution to bring down the moisture level prior to drying process. During the process of osmotic dehydration, two counter current passes, where water flow from food into the solution and water soluble solute transfer from solution into the food takes place thereby infusion of vitamins, minerals, sugars, organic acids, volatiles and flavor compounds from food into the solution was observed. These changes are responsible for the overall quality of the dehydrated product. The percent weight reduction (WR), solid gain (SG) and water loss (WL) of all the $T_{1}$ and $T_{2}$ samples resulted in significant increments with the increase in time from $90^{\text {th }}$ to $540^{\text {th }} \mathrm{min}$ and did not increase beyond $540^{\text {th }}$ min up to $720^{\text {th }}$ min of osmotic dehydration, hence the values remained plateau $(\mathrm{p} \leq 0.05)$. The $\mathrm{WR}, \mathrm{SG}$ and $\mathrm{WL}$ were found to be slightly increased in $\mathrm{T}_{1}$ and $\mathrm{T}_{2}$ samples impregnated with functional

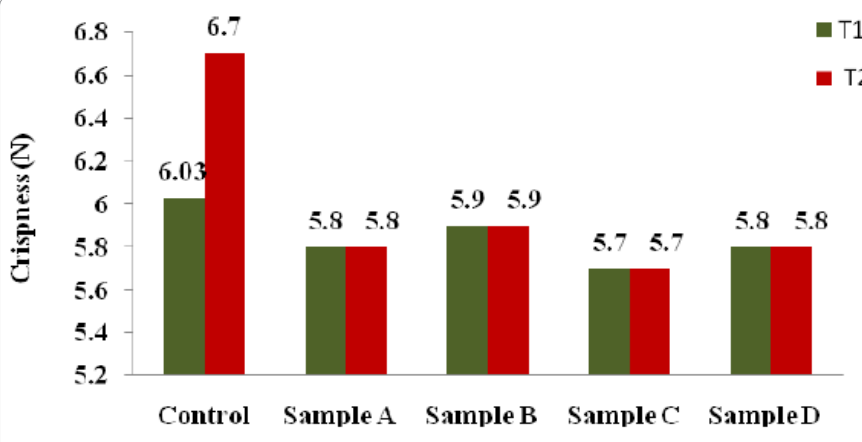

Figure 4: Texture analysis-crispiness $(N)$ of the ready-to-eat coconut based snack. 
filtrate of C and D. This is due to the uptake of more sugars from the carrot and beetroot infusion representing the plentiful sources of sugars.

Weight reduction (\%) of the ready-to-eat coconut based snack: Table 2 describes the weight reduction property of the ready-to-eat coconut based snack. It was depicted that gradual decrease in weight reduction was shown from every 90th min to 540th min. The most significant changes was observed in weight reduction in control coconut snack from 90th $\mathrm{min}$ (7.11) to 540th $\mathrm{min}$ (42.70) when subjected to T1, while in case of $\mathrm{T}_{2}$ samples, the range was 7.52-42.68.

Similarly for all the functionally impregnated ready-to-eat coconut based snacks, the maximum weight reduction was observed with significant difference at $p \leq 0.05$ from $90 \mathrm{~min}$ to $540 \mathrm{~min}$, viz., $\mathrm{T}_{1} \mathrm{~A}-$ - (7.16 to 43.11$), \mathrm{T}_{2} \mathrm{~A}-(9.24$ to 44.13$), \mathrm{T}_{1} \mathrm{~B}-$ (7.16 to 43.21$), \mathrm{T}_{2} \mathrm{~B}-$ (9.33 to 43.42$), \mathrm{T}_{1} \mathrm{C}-(7.22$ to 43.36$), \mathrm{T}_{2} \mathrm{C}-(9.64$ to 44.14$)$ and $\mathrm{T}_{1} \mathrm{D}-$ (6.84 to 43.36$)$, $\mathrm{T}_{2} \mathrm{D}$ (9.64 to 44.14$)$. However the weight reduction of all the coconut samples did not increase beyond 540 minutes of osmotic dehydration. The weight reduction in the functional filtrate impregnated with samples $\mathrm{C}$ and $\mathrm{D}$ was found to be slightly increased. This might be due to the uptake of more sugars from the carrot and beetroot infusions, representing the presence of sugars in these roots which is also supported by Rastogi et al. [34]. The finding was similar to the outcome of Torreggiani et al. [1], who stated that due to extra solute incorporation there is an increase in the weight reduction with increase in time. The result of the present study was in par with the outcome of Bchiret al. [35] was stated that increment in WR of pomegranate seeds was noted with increase in immersion time by using various concentration of date juices at the initial state of osmotic dehydration whilst the maximum changes in the above parameters took place at 20 min of the osmotic dehydration process. The greatest weight reduction was observed up to $40 \%$ until 120 minutes of osmotic dehydration.

Welti et al. [5] stated that the solute concentration of fruits increased by the most constructive technology i.e. osmotic dehydration or osmotic concentration. This technique includes the mechanism of placing fruits or vegetables in hypertonic salt or sugar solutions of soluble solids, ensuing water removal and increment in soluble solids content by solute absorption, which ultimately results in net reduction in weight of solid foods.

Solids gain (\%) of the ready-to-eat coconut based snack: The solids gain of the ready-to-eat coconut based snack is discussed in Table 3. On analyzing the solid gain of the samples using analysis of variance reveals that irrespective of the osmotic impregnations and drying methods adopted all the impregnated samples and control samples found to contain of increased values corresponding to the progress in osmotic dehydration process which was observed for a duration from every $90^{\text {th }} \mathrm{min}$ to $540^{\text {th }} \mathrm{min}$, beyond which no change was noted significantly. The mean solid gain content of impregnated samples $\mathrm{C}$ and $\mathrm{D}$ subjected to drying methods $\mathrm{T}_{1}$ and $\mathrm{T}_{2}$ ( $\mathrm{T}_{1} \mathrm{C}-0.41$ to $2.44, \mathrm{~T}_{2} \mathrm{C}-$ 0.49 to $2.97, \mathrm{~T}_{1} \mathrm{D}-0.41$ to $2.44, \mathrm{~T}_{2} \mathrm{D}-0.49$ to 2.97 ) were observed with significant increments during osmotic dehydration process (90 to 540 min) which were greater $(p \leq 0.05)$ than solid gain content possessed by impregnated samples $A$ ( $\mathrm{T}_{1} \mathrm{~A}-0.23$ to $1.39, \mathrm{~T}_{2} \mathrm{~A}-0.29$ to 2.23 ) B ( $\mathrm{T}_{1} \mathrm{~B}-$ 0.31 to $1.78, \mathrm{~T}_{2} \mathrm{~B}-0.29$ to 2.23 ) and Control ( $\mathrm{T}_{1}$ Control- 0.225 to 1.35 , $\mathrm{T}_{2}$ Control- 0.263 to 1.88 ).

The slight increment of solid gain in impregnated samples $C$ and $\mathrm{D}$ could be due to the uptake of more sugars from filtrates of carrot and beetroot infusions which is described as chief sources of

\begin{tabular}{|c|c|c|c|c|c|c|c|c|c|c|c|c|c|c|c|}
\hline \multirow{3}{*}{$\begin{array}{c}\text { Filtrate of } \\
\text { functional } \\
\text { ingredients }\end{array}$} & \multirow{2}{*}{\multicolumn{2}{|c|}{$\frac{L^{*}}{\text { Drying method }}$}} & \multirow{3}{*}{ p-value } & a & & \multirow{3}{*}{ p-value } & & $b^{*}$ & \multirow{3}{*}{ p-value } & \multirow{2}{*}{\multicolumn{2}{|c|}{\begin{tabular}{|c|} 
Chroma \\
Drying method
\end{tabular}}} & \multirow{2}{*}{\multicolumn{2}{|c|}{$\frac{\Delta \mathrm{E}}{\text { Drying method }}$}} & \multirow{2}{*}{\multicolumn{2}{|c|}{\begin{tabular}{|c|} 
Hue angle \\
Drying method
\end{tabular}}} \\
\hline & & & & \multicolumn{2}{|c|}{ Drying method } & & \multicolumn{2}{|c|}{ Drying method } & & & & & & & \\
\hline & T1 & T2 & & T1 & T2 & & T1 & T2 & & T1 & T2 & T1 & T2 & T1 & T2 \\
\hline Control & $66.71 \pm 0.02$ & $69.83 \pm 0.07$ & $0.000^{*}$ & $-.643 \pm 0.02$ & $-0.78 \pm 0.01$ & $0.000^{*}$ & $4.60 \pm 0.003$ & $4.88 \pm 0.03$ & $0.000^{*}$ & 4.64 & 4.94 & - & - & -82.04 & -80.92 \\
\hline A & $57.45 \pm 0.13$ & $61.45 \pm 0.06$ & $0.000^{*}$ & $-1.90 \pm 0.11$ & $-1.19 \pm 0.04$ & $0.000^{*}$ & $8.60 \pm 0.040$ & $9.63 \pm 0.17$ & $0.001^{*}$ & 10.50 & 9.70 & 10.17 & 9.64 & -77.55 & -82.95 \\
\hline B & $61.80 \pm 0.35$ & $61.80 \pm 0.10$ & $1.00^{\mathrm{NS}}$ & $-0.83 \pm 0.005$ & $-0.967 \pm 0.01$ & $0.000^{*}$ & $6.60 \pm 0.30$ & $5.79 \pm 0.07$ & $0.010^{*}$ & 6.65 & 5.87 & 5.3 & 8.08 & -82.83 & -80.52 \\
\hline C & $60.01 \pm 0.01$ & $69.94 \pm 0.06$ & $0.000^{*}$ & $1.621 \pm 0.0$ & $1.12 \pm 0.01$ & $0.000^{*}$ & $13.9 \pm 0.003$ & $13.9 \pm 0.003$ & $1.00^{\mathrm{NS}}$ & 13.90 & 13.94 & 11.68 & 9.21 & 83.34 & -85.39 \\
\hline $\mathrm{D}$ & $53.89 \pm 0.06$ & $57.90 \pm 0.004$ & $0.000^{*}$ & $11.05 \pm 0.04$ & $10.09 \pm 0.01$ & $0.000^{*}$ & $13.45 \pm 0.16$ & $13.86 \pm 0.08$ & $0.017^{*}$ & 17.40 & 17.14 & 14.92 & 18.5 & 50.59 & 53.95 \\
\hline
\end{tabular}

All values are means of triplicate determinations \pm standard deviation (SD), $T_{1}$ - Hot Air Oven Drying, $\mathrm{T}_{2}$ - Freeze

Drying Sample A-Mentha piperita, Sample B-Zingiber officinale, Sample C-Daucus carota and Sample D-Beta

vulgaris filtrate impregnated coconut based snack, NS- Not Significant, * Significant at $p \leq 0.05$

Table 1: Color values of the ready-to-eat coconut based snack.

\begin{tabular}{|c|c|c|c|c|c|c|c|c|c|c|c|}
\hline \multirow{2}{*}{ Samples } & \multirow{2}{*}{$\begin{array}{l}\text { Drying } \\
\text { method }\end{array}$} & \multicolumn{9}{|c|}{ Time (min) } & \multirow{2}{*}{ p-value } \\
\hline & & 0 & 90 & 180 & 270 & 360 & 450 & 540 & 630 & 720 & \\
\hline \multirow{2}{*}{ Control } & T1 & $1.42 \pm 0.02$ & $7.11 \pm 0.09$ & $14.23 \pm 0.06$ & $21.35 \pm 0.12$ & $28.46 \pm 0.1$ & $35.58 \pm 0.17$ & $42.7 \pm 0.6$ & $42.7 \pm 0.6$ & $42.70 \pm 0.6$ & $0.001^{*}$ \\
\hline & T2 & $1.624 \pm 0.03$ & $7.52 \pm 0.02$ & $14.45 \pm 0.013$ & $21.53 \pm 0.103$ & $28.56 \pm 0.15$ & $35.59 \pm 0.31$ & $42.68 \pm 0.2$ & $42.68 \pm 0.2$ & $42.68 \pm 0.2$ & $0.002^{*}$ \\
\hline \multirow{2}{*}{$\mathbf{A}$} & T1 & $1.440 \pm 0.08$ & $7.16 \pm 0.02$ & $14.11 \pm 0.02$ & $21.49 \pm 0.19$ & $28.86 \pm 0.13$ & $35.89 \pm 0.14$ & $43.11 \pm 0.1$ & $43.11 \pm 0.1$ & $43.11 \pm 0.1$ & $0.003^{*}$ \\
\hline & T2 & $2.098 \pm 0.01$ & $9.24 \pm 0.02$ & $18.12 \pm 0.01$ & $27.13 \pm 0.120$ & $32.01 \pm 0.09$ & $38.42 \pm 0.06$ & $44.13 \pm 0.1$ & $44.13 \pm 0.1$ & $44.13 \pm 0.1$ & $0.001^{*}$ \\
\hline \multirow{2}{*}{ B } & T1 & $1.44 \pm 0.04$ & $7.16 \pm 0.01$ & $14.11 \pm 0.08$ & $22.01 \pm 0.05$ & $28.98 \pm 0.21$ & $36.07 \pm 0.05$ & $43.21 \pm 0.1$ & $43.21 \pm 0.10$ & $43.21 \pm 0.1$ & $0.005^{*}$ \\
\hline & T2 & $2.15 \pm 0.02$ & $9.33 \pm 0.02$ & $18.21 \pm 0.01$ & $27.22 \pm 0.15$ & $32.14 \pm 0.08$ & $37.82 \pm 0.10$ & $43.42 \pm 0.15$ & $43.42 \pm 0.15$ & $43.42 \pm 0.15$ & $0.001^{*}$ \\
\hline \multirow{2}{*}{ C } & T1 & $1.44 \pm 0.01$ & $7.22 \pm 0.01$ & $14.44 \pm 0.12$ & $22.08 \pm 0.30$ & $29.09 \pm 0.20$ & $36.08 \pm 0.17$ & $43.36 \pm 0.10$ & $43.36 \pm 0.10$ & $43.36 \pm 0.1$ & $0.003^{*}$ \\
\hline & T2 & $2.38 \pm 0.09$ & $9.64 \pm 0.01$ & $18.41 \pm 0.01$ & $27.52 \pm 0.110$ & $32.34 \pm 0.11$ & $38.11 \pm 0.09$ & $44.14 \pm 0.1$ & $44.14 \pm 0.1$ & $44.14 \pm 0.1$ & 0.001 \\
\hline \multirow{2}{*}{ D } & T1 & $1.44 \pm 0.020$ & $6.84 \pm 0.02$ & $14.24 \pm 0.02$ & $22.08 \pm 0.150$ & $29.09 \pm 0.23$ & $36.08 \pm 0.20$ & $43.36 \pm 0.2$ & $43.36 \pm 0.24$ & $43.36 \pm 0.24$ & 0.002 \\
\hline & T2 & $2.38 \pm 0.09$ & $9.64 \pm 0.01$ & $18.41 \pm 0.01$ & $27.52 \pm 0.110$ & $32.34 \pm 0.11$ & $38.11 \pm 0.09$ & $44.14 \pm 0.1$ & $44.14 \pm 0.1$ & $44.14 \pm 0.1$ & $0.002^{*}$ \\
\hline
\end{tabular}

All values are means of triplicate determinations \pm standard deviation (SD), $\mathrm{T}_{1}$-Hot Air Oven Drying, $\mathrm{T}_{2}$-Freeze Drying Sample A-Mentha piperita, Sample B-Zingiber officinale, Sample $C$-Daucus carota and Sample D-Beta vulgaris filtrate impregnated coconut based snack, Rows followed by different alphabets are *Significantly different $(p \leq 0.05)$, NS- Not Significant by LSD

Table 2: Weight reduction (\%) of the ready-to-eat coconut based snack. 
sugars according to Pavlov et al. [36]. The finding was similar to the outcome of Torreggiani et al. [1]who explained that due to extra solute incorporation the solid gain increases with increase in time. Time has considerable effect on solid gain (sugar uptake) and moisture loss. The finding of the present study was consistent with the outcome of Bchiret al. [35] who stated that osmotic dehydration resulted in increment of WR, SG and WL of pomegranate seeds with increase in immersion time by using various concentrations of date juices. The maximum changes in the above parameters took place at $20 \mathrm{~min}$ of the osmotic dehydration process. The increment in $\mathrm{WR}$ was observed in the pomegranate seeds whereas SG increased at significant level up to $6 \%$ during OD process and remained stable at the end of the process.

The significant increase $(p \leq 0.05)$ in SG in the present study was coinciding with the fact suggested by Delgado and Rubiolo [27] and Fathi et al. [28] who observed that SG during osmotic dehydration might be obtained by the movement of sucrose to the pomegranate seeds through cell wall and accumulation between cell wall and its membranes due to existence of sugar between the food and the osmotic medium. The osmotic medium found to contain more sucrose than the seeds. Bchiret al. [35] stated that the sucrose present in date juice influenced the texture of the seeds and was contributing about $39 \%$ of the total sucrose content added additionally in the osmotic syrup which is the contributing factor for increase in solid gain. Also Lombard et al. [37] studied the effects of osmotic dehydration on mass transfer kinetics of pine apple cylinders. The cylinders found to contain increased solid content (Solid gain) after 240th min of osmotic dehydration process [38].

Water loss (\%) of the ready-to-eat coconut based snack: Table 4 discusses the water loss property of the ready-to-eat coconut based snack. The water loss property of the samples was computed based on the summation of weight reduction and solid gain values. It was inferred from the above results, samples C and D infused with Daucus carota and Beta vulgaris extracts possessed greater SG and WR values which ultimately resulted in maximum water loss property $\left(\mathrm{T}_{1} \mathrm{C}\right.$ 7.6 to $45.79, \mathrm{~T}_{2} \mathrm{C}-10.2$ to $47.11, \mathrm{~T}_{1} \mathrm{D}-7.25$ to $45.8, \mathrm{~T}_{2} \mathrm{D}-10.2$ to 47.11 ) which was observed with significant difference at $p \leq 0.05$ at $90^{\text {th }} \mathrm{min}$ and $540^{\text {th }}$ min on account of their prolific natural presence of sugars, whereas a slight decline in values were noted in samples $\mathrm{A}\left(\mathrm{T}_{1} \mathrm{~A}-7.39\right.$ to $44.51, \mathrm{~T}_{2} \mathrm{~A}-9.52$ to 46.36 ), $\mathrm{B}$ ( $\mathrm{T}_{1} \mathrm{~B}-7.47$ to $44.99, \mathrm{~T}_{2} \mathrm{~B}-9.42$ to 45.65 ) and Control ( $\mathrm{T}_{1}$ Control-7.34 to 44.05, $\mathrm{T}_{2}$ Control-7.79 to 44.57). The finding was similar to the outcome of Torreggiani et al. [1] who stated that due to extra solute incorporation there was an increase in the water loss (\%) with increase in time. Thus the results of analysis of variance showed that the sugar infused osmotic solutions either with or without impregnation of functional ingredients had a significant $(p \leq 0.05)$ effect on water loss of the ready-to-eat coconut based snack.

The increment in water loss of the samples in the present research was in reliant with the findings of Kowalska et al. [12] who reported that sucrose, glucose and starch syrup upon osmotic dehydration of pumpkin for $180^{\text {th }}$ min showed an increment of maximum water loss and principally showed increment in solid gains when compared with samples with no pre-treatments carried out like blanching and freezing. Delgado and Rubiolo [27] and Fathi et al. [28] reported that osmotic dehydration generally results in water loss in with significant reduction in weight and solid gain accompanied by structural changes in cell wall tissue matrix of the solid foods with compaction of the surface layers with enhanced mass transfer resistance for solids and water.

In the present study, the $100 \%$ sugar infusion showed maximum water loss property during osmotic dehydration, which was related to the concept of Fathi et al. [28] where osmotic dehydration is favored over solid uptake that lead to mass loss of pear fruit. It was found that increase in syrup concentration from 35 to $45^{\circ}$ Brix and syrup fruit ratio from 1 to 2 , there was substantial alteration in water loss from $18.09 \%$ to $23.18 \%$, mass loss from $9.26 \%$ to $20.06 \%$ and solid gain from 13.59 to $16.38 \%$. Bchir et al.[35] reported that, the various temperatures 30, 40 and $50^{\circ} \mathrm{C}$ had different impact on mass transfer kinetics of pomegranate seeds, which was immersed in $50^{\circ}$ Brix glucose, sucrose and the mixture of the two (50:50). Effective water loss was noted at $37 \%$ in glucose, $46 \%$ in sucrose and $41 \%$ in mixture of solution (50:50).

The findings of the present study is in line with SantacruzVázquezet al.[39] who reported that there exists strong relationship between higher concentrations of sugar and increment in water loss ratios observed in some fruits of tropical origin such as melon, papaya and guava and also agreed that efficient osmotic dehydration achieved depends on concentration of sugar used. Lombard et al. [3] examined the sensory and stability of the osmotic dehydrated products which depend extremely on efficient water loss and solute gain. The net yield of the osmotic dehydration process will result in the summation of two counter current mass fluxes. Optimization process plays a vital role in obtaining maximum yield with optimum sensory traits of the food products.

Rehydration characteristics of the ready-to-eat coconut based snack: The drying process is evaluated by two mandatory physical factors such as appearance of the vegetables and the time required for reconstituting the vegetables. Also the reconstitution of dried fruits or vegetables depends mainly on the internal structure of dried food pieces and the degree of damage of water-holding components on drying. The reconstitution of dried vegetables become faster, when the food has an open and porous structure. The intrinsic factors which influence rehydration of dried food products involves product chemical composition, pre-drying treatment, formulation of products, drying conditions and techniques etc. The extrinsic factors constitute composition of osmotic medium, temperature and hydrodynamic conditions. These factors affect the tissue composition of plants, thereby causing impairment to the rehydration characteristics.

Rehydration ratio of the ready-to-eat coconut based snack: Table 5 explains the rehydration ratio of the ready-to-eat coconut based snack rehydration consists of two processes such as water absorption and leaching of solutes. A perfect rehydration yields a product with similar proximate principles of the raw foods.

The significant increase in Rehydration Ratio (RR) was observed from every $5^{\text {th }}$ min to $20^{\text {th }}$ min of water absorption process at $p \leq 0.05$ level. The superficial changes in RR was observed during 5 min (1.21) to $20 \mathrm{~min}$ (1.92) in case of $\mathrm{T}_{1}$ samples and among the $\mathrm{T}_{2}$ samples, the range was 1.59 during $5^{\text {th }}$ min -2.06 during $20^{\text {th }}$ min was obtained within 15 minutes itself, beyond which no water absorption was noted. The quick absorption of water by freeze dried samples was due to its porous structure.

In the present study, the coconut slices were pre-treated using sugar solution which increased the rehydration property. This outcome was similar to the finding of Leszczyk et al. [40] who indicated that rehydration of osmotic treated (salt and sucrose) celery prevented shrinkage due to the mechanical and structural strength provided by the osmotic agents on drying, there by increased water absorption. The pre-treatment of coconut slices using osmotic dehydration followed by drying methods increased the water absorption phenomenon. Leszczyk et al. [40] reported that rehydration increased water absorption of dried 
Citation: Sivasakthi M, Sangeetha N (2015) A Comparative Study of the Physico-Chemical Characteristics of the Ready-to Eat Coconut Based Snack. J Food Process Technol 6: 489. doi:10.4172/2157-7110.1000489

Page 8 of 10

\begin{tabular}{|c|c|c|c|c|c|c|c|c|c|c|c|}
\hline \multirow{2}{*}{ Samples } & \multirow{2}{*}{$\begin{array}{l}\text { Drying } \\
\text { method }\end{array}$} & \multicolumn{9}{|c|}{ Time (min) } & \multirow{2}{*}{$p$-valu } \\
\hline & & 0 & 90 & 180 & 270 & 360 & 450 & 540 & 630 & 720 & \\
\hline \multirow{2}{*}{ Control } & T1 & $0.045 \pm 0.008$ & $225 \pm 0.009$ & $451 \pm 0.005$ & $0.675 \pm 0.006$ & $901 \pm 0.008$ & $1.13 \pm 0.017$ & $1.35 \pm 0.007$ & $1.35 \pm 0.007$ & $1.35 \pm 0.007$ & $.001^{*}$ \\
\hline & T2 & $0.066 \pm 0.009$ & $0.263 \pm 0.005$ & $0.487 \pm 0.009$ & $0.683 \pm 0.004$ & $1.467 \pm 0.012$ & $1.67 \pm 0.009$ & $1.88 \pm 0.026$ & $1.88 \pm 0.026$ & $1.88 \pm 0.026$ & $0.002^{*}$ \\
\hline \multirow{2}{*}{ A } & T1 & $0.048 \pm 0.011$ & $0.23 \pm 0.01$ & $0.468 \pm 0.012$ & $0.699 \pm 0.02$ & $0.930 \pm 0.06$ & $1.161 \pm 0.01$ & $1.39 \pm 0.01$ & $1.39 \pm 0.01$ & $1.39 \pm 0.01$ & $.001^{*}$ \\
\hline & T2 & $0.087 \pm 0.006$ & $0.29 \pm 0.01$ & $0.524 \pm 0.003$ & $0.777 \pm 0.008$ & $1.529 \pm 0.016$ & $1.98 \pm 0.009$ & $2.23 \pm 0.02$ & $2.23 \pm 0.02$ & $2.23 \pm 0.02$ & $.003^{*}$ \\
\hline & T1 & $0.063 \pm 0.005$ & $0.31 \pm 0.01$ & $0.599 \pm 0.001$ & $0.907 \pm 0.006$ & $0.996 \pm 0.009$ & $1.489 \pm 0.012$ & $1.78 \pm 0.01$ & $1.78 \pm 0.01$ & $1.78 \pm 0.01$ & $0.004^{*}$ \\
\hline & T2 & $0.088 \pm 0.01$ & $0.29 \pm 0.015$ & $0.527 \pm 0.01$ & $0.778 \pm 0.013$ & $1.528 \pm 0.016$ & $1.975 \pm 0.009$ & $2.23 \pm 0.01$ & $2.23 \pm 0.01$ & $2.23 \pm 0.0$ & $.002^{*}$ \\
\hline & T1 & $0.085 \pm 0.01$ & $0.41 \pm 0.02$ & $0.816 \pm 0.006$ & $1.219 \pm 0.013$ & $1.629 \pm 0.018$ & $2.028 \pm 0.01$ & $2.44 \pm 0.01$ & $2.44 \pm 0.01$ & $2.44 \pm 0.01$ & $0.001^{*}$ \\
\hline & T2 & $0.283 \pm 0.00$ & $0.49 \pm 0.013$ & $0.875 \pm 0.012$ & $0.977 \pm 0.011$ & $1.966 \pm 0.009$ & $2.544 \pm 0.008$ & $2.97 \pm .001$ & $2.97 \pm 0.01$ & $2.97 \pm 0.01$ & $0.003^{*}$ \\
\hline & T1 & $0.088 \pm 0.009$ & $0.41 \pm 0.006$ & $0.82 \pm 0.06$ & $1.22 \pm 0.011$ & $1.635 \pm 0.023$ & $2.032 \pm 0.007$ & $2.44 \pm 0.005$ & $2.44 \pm 0.005$ & $2.44 \pm 0.005$ & $0.005^{*}$ \\
\hline & T2 & $0.283 \pm 0.005$ & $0.49 \pm 0.013$ & $0.875 \pm 0.012$ & $0.977 \pm 0.011$ & $1.966 \pm 0.009$ & $2.544 \pm 0.008$ & $2.97 \pm 0.01$ & $2.97 \pm 0.01$ & $2.97 \pm 0.01$ & $0.003^{*}$ \\
\hline
\end{tabular}

All values are means of triplicate determinations \pm standard deviation (SD), $T_{1}$-Hot Air Oven Drying, $T_{2}$-Freeze Drying Sample A-Mentha piperita, Sample B-Zingibe officinale, Sample C-Daucus carota and Sample D-Beta vulgaris filtrate impregnated coconut based snack, Rows followed by different alphabets are *Significantly different $(p \leq 0.05)$, NS- Not Significant by LSD

Table 3: Solids gain (\%) of the ready-to-eat coconut based snack.

\begin{tabular}{|c|c|c|c|c|c|c|c|c|c|c|c|}
\hline \multirow{2}{*}{ Samples } & \multirow{2}{*}{$\begin{array}{l}\text { Drying } \\
\text { method }\end{array}$} & \multicolumn{9}{|c|}{ Time (min) } & \multirow{2}{*}{ p-value } \\
\hline & & 0 & 90 & 180 & 270 & 360 & 450 & 540 & 630 & 720 & \\
\hline \multirow{2}{*}{ Control } & T1 & $1.47 \pm 0.09$ & $7.34 \pm 0.06$ & $14.68 \pm 0.14$ & $22.02 \pm 0.2$ & $29.4 \pm 0.00$ & $36.71 \pm 0.02$ & $44.05 \pm 0.02$ & $44.05 \pm 0.02$ & $44.05 \pm 0.02$ & $0.001^{*}$ \\
\hline & T2 & $1.69 \pm 0.01$ & $7.79 \pm 0.02$ & $14.94 \pm 0.02$ & $22.22 \pm 0.1$ & $30.03 \pm 0.01$ & $37.26 \pm 0.01$ & $44.57 \pm 0.01$ & $44.57 \pm 0.01$ & $44.57 \pm 0.01$ & $0.005^{*}$ \\
\hline \multirow{2}{*}{ A } & T1 & $1.49 \pm 0.01$ & $7.39 \pm 0.02$ & $14.58 \pm 0.01$ & $22.19 \pm 0.02 d$ & $29.79 \pm 0.08$ & $37.05 \pm 0.04$ & $44.51 \pm 0.02$ & $44.51 \pm 0.02$ & $44.51 \pm 0.02$ & $0.001^{*}$ \\
\hline & T2 & $2.18 \pm 0.01$ & $9.52 \pm 0.01$ & $18.65 \pm 0.2$ & $27.91 \pm 0.3$ & $33.5 \pm 0.01$ & $40.39 \pm 0.01$ & $46.36 \pm 0.04$ & $46.36 \pm 0.04$ & $46.36 \pm 0.01$ & $0.003^{*}$ \\
\hline \multirow{2}{*}{ B } & T1 & $1.50 \pm 0.01$ & $7.47 \pm 0.10$ & $14.71 \pm 0.1$ & $22.9 \pm 0.05$ & $29.98 \pm 0.01$ & $37.56 \pm 0.01$ & $44.99 \pm 0.01$ & $44.99 \pm 0.01$ & $44.99 \pm 0.01$ & $0.005^{*}$ \\
\hline & T2 & $2.24 \pm 0.00$ & $9.42 \pm 0.05$ & $18.74 \pm 0.06$ & $27.9 \pm 0.07$ & $33.67 \pm 0.01$ & $39.79 \pm 0.02$ & $45.65 \pm 0.00$ & $45.65 \pm 0.00$ & $45.65 \pm 0.00$ & $0.001^{*}$ \\
\hline \multirow{2}{*}{ C } & T1 & $1.53 \pm 0.00$ & $7.6 \pm 0.01$ & $15.3 \pm 0.009$ & $23.29 \pm 0.01$ & $30.7 \pm 0.01$ & $38.11 \pm 0.07$ & $45.79 \pm 0.02$ & $45.79 \pm 0.02$ & $45.79 \pm 0.02$ & $0.001^{*}$ \\
\hline & T2 & $2.66 \pm 0.01$ & $10.2 \pm 0.00$ & $19.3 \pm 0.01$ & $28.5 \pm 0.01$ & $34.3 \pm 0.01$ & $40.65 \pm 0.02$ & $47.11 \pm 0.01$ & $47.11 \pm 0.01$ & $47.11 \pm 0.01$ & $0.003^{*}$ \\
\hline \multirow{2}{*}{ D } & T1 & $1.53 \pm 0.00$ & $7.25 \pm 0.04$ & $15.06 \pm 0.00$ & $23.30 \pm 0.01$ & $30.72 \pm 0.01$ & $38.11 \pm 0.07$ & $45.8 \pm 0.01$ & $45.8 \pm 0.01$ & $45.8 \pm 0.01$ & $0.003^{*}$ \\
\hline & T2 & $2.66 \pm 0.01$ & $10.2 \pm 0.00$ & $19.3 \pm 0.01$ & $28.5 \pm 0.01$ & $34.3 \pm 0.01$ & $40.65 \pm 0.01$ & $47.11 \pm 0.01$ & $47.11 \pm 0.01$ & $47.11 \pm 0.01$ & $0.004^{*}$ \\
\hline
\end{tabular}

All values are means of triplicate determinations \pm standard deviation (SD), $\mathrm{T}_{1}$ - Hot Air Oven Drying, $\mathrm{T}_{2}$-Freeze Drying Sample A-Mentha piperita, Sample B-Zingiber officinale, Sample $C$-Daucus carota and Sample $D$-Beta vulgaris filtrate impregnated coconut based snack, Rows followed by different alphabets are *Significantly different $(p \leq 0.05)$, NS-Not Significant by LSD

Table 4: Water loss (\%) of the ready-to-eat coconut based snack.

\begin{tabular}{|c|c|c|c|c|c|c|c|c|c|}
\hline \multirow{2}{*}{ Samples } & \multirow{2}{*}{ Drying method } & \multicolumn{7}{|c|}{ Time (min) } & \multirow{2}{*}{ p-value } \\
\hline & & 0 & 5 & 10 & 15 & 20 & 25 & 30 & \\
\hline \multirow{2}{*}{ Control } & T1 & $1.11 \pm 0.006$ & $1.21 \pm 0.009$ & $1.232 \pm 0.006$ & $1.430 \pm 0.07$ & $1.92 \pm 0.011$ & $1.92 \pm 0.011$ & $1.92 \pm 0.011$ & $0.001^{*}$ \\
\hline & T2 & $1.319 \pm 0.010$ & $1.595 \pm 0.004$ & $1.614 \pm 0.003$ & $1.944 \pm 0.006$ & $1.98 \pm 0.013$ & $1.98 \pm 0.013$ & $1.98 \pm 0.013$ & $0.003^{*}$ \\
\hline \multirow{2}{*}{ A } & T1 & $1.24 \pm 0.005$ & $1.417 \pm 0.006$ & $1.497 \pm 0.012$ & $1.503 \pm 0.01$ & $1.901 \pm 0.005$ & $1.901 \pm 0.005$ & $1.901 \pm 0.005$ & $0.002^{*}$ \\
\hline & T2 & $1.312 \pm 0.003$ & $1.582 \pm 0.006$ & $1.608 \pm 0.001$ & $1.95 \pm 0.007$ & $1.99 \pm 0.007$ & $1.99 \pm 0.007$ & $1.99 \pm 0.007$ & $0.004^{*}$ \\
\hline \multirow{2}{*}{ B } & T1 & $1.435 \pm 0.006$ & $1.508 \pm 0.184$ & $1.79 \pm 0.01$ & $1.89 \pm 0.011$ & $1.92 \pm 0.012$ & $1.916 \pm 0.012$ & $1.916 \pm 0.012$ & $0.000^{*}$ \\
\hline & T2 & $1.346 \pm 0.005$ & $1.59 \pm 0.008$ & $1.63 \pm 0.007$ & $1.97 \pm 0.003$ & $2.06 \pm 0.00$ & $2.06 \pm 0.005$ & $2.06 \pm 0.005$ & $0.002^{*}$ \\
\hline \multirow{2}{*}{ C } & T1 & $1.3 \pm 0.014$ & $1.467 \pm 0.013$ & $1.595 \pm 0.013$ & $1.878 \pm 0.012$ & $1.914 \pm 0.008$ & $1.914 \pm 0.008$ & $1.914 \pm 0.008$ & $0.001^{*}$ \\
\hline & T2 & $1.32 \pm 0.009$ & $1.59 \pm 0.017$ & $1.618 \pm 0.01$ & $1.960 \pm 0.003$ & $2.06 \pm 0.006$ & $2.06 \pm 0.00$ & $2.06 \pm 0.006$ & $0.002^{*}$ \\
\hline \multirow[t]{2}{*}{ D } & T1 & $1.12 \pm 0.00$ & $1.502 \pm 0.00$ & $1.55 \pm 0.00$ & $1.71 \pm 0.00$ & $1.892 \pm 0.00$ & $1.892 \pm 0.00$ & $1.89 \pm 0.00$ & $0.003^{*}$ \\
\hline & T2 & $1.30 \pm 0.014$ & $1.580 \pm 0.004$ & $1.59 \pm 0.006$ & $1.94 \pm 0.006$ & $1.984 \pm 0.003$ & $1.984 \pm 0.003$ & $1.98 \pm 0.003$ & $0.003^{*}$ \\
\hline
\end{tabular}

All values are means of triplicate determinations \pm standard deviation (SD), Sample A-Mentha piperita, $\mathrm{T}_{1}-\mathrm{H}_{\mathrm{H}}$

Air Oven Drying, $T_{2}$ - Freeze Drying Sample B-Zingiber officinale, Sample C-Daucus carota and Sample D-Beta vulgaris filtrate impregnated coconut based snack, Rows followed by different alphabets are *Significantly different $(p \leq 0.05)$, NS- Not Significant by LSD

Table 5: Rehydration ratio of the ready-to-eat coconut based snack.

foods up to $42.5 \%$ to $60.5 \%$. He studied that rehydration increased the water absorption property of celery after the pre-treatment process of osmotic dehydration. In addition, Nindo et al. [21] reported that soaking of dried onions for a period of 20 minutes resulted in an increase in reconstitution property.

Coefficient of Rehydration of the ready-to-eat coconut based snack: The Coefficient of Rehydration (CR) of the samples showed increment from every 5 to 20 min. The significant change in CR ( $\leq$
$0.05)$ was noted in $\mathrm{T}_{1}$ samples during $5 \mathrm{~min}(0.559)$ to $20 \mathrm{~min}(0.9)$ whilst the $\mathrm{T}_{2}$ samples attained the maximum values within $5 \mathrm{~min}(0.64)$ to $15 \mathrm{~min}(0.95)$ itself. The quicker water absorption characteristics $\mathrm{RR}$ and CR were noted in freeze dried samples due to its porous and hygroscopic nature of tissue matrix (Table 6). Tunde-Akintunde [41] reported that rehydration ratio and coefficient of rehydration characteristics could be increased with increase in temperature and time. In the present study, the samples were dried using hot-air oven 
Citation: Sivasakthi M, Sangeetha N (2015) A Comparative Study of the Physico-Chemical Characteristics of the Ready-to Eat Coconut Based Snack. J Food Process Technol 6: 489. doi:10.4172/2157-7110.1000489

Page 9 of 10

\begin{tabular}{|c|c|c|c|c|c|c|c|c|c|}
\hline \multirow{2}{*}{ Samples } & \multirow{2}{*}{ Drying method } & \multicolumn{7}{|c|}{ Time (min) } & \multirow{2}{*}{ p-value } \\
\hline & & 0 & 5 & 10 & 15 & 20 & 25 & 30 & \\
\hline \multirow{2}{*}{ Control } & T1 & $0.515 \pm 0.01$ & $0.559 \pm 0.014$ & $0.57 \pm 0.012$ & $0.66 \pm 0.09$ & $0.9 \pm 0.00$ & $0.9 \pm 0.00$ & $0.9 \pm 0.00$ & $0.003^{*}$ \\
\hline & T2 & $0.618 \pm 0.01$ & $0.75 \pm 0.040$ & $0.756 \pm 0.01$ & $0.921 \pm 0.01$ & $0.94 \pm 0.03$ & $0.94 \pm 0.03$ & $0.94 \pm 0.03$ & $0.002^{*}$ \\
\hline \multirow{2}{*}{ A } & T1 & $0.579 \pm 0.01$ & $0.661 \pm 0.007$ & $0.696 \pm 0.00$ & $0.70 \pm 0.01$ & $0.886 \pm 0.01$ & $0.886 \pm 0.01$ & $0.886 \pm 0.009$ & $0.003^{*}$ \\
\hline & T2 & $0.613 \pm 0.01$ & $0.74 \pm 0.03$ & $0.752 \pm 0.01$ & $0.912 \pm 0.01$ & $0.93 \pm 0.04$ & $0.93 \pm 0.04$ & $0.93 \pm 0.04$ & $0.004^{*}$ \\
\hline \multirow{2}{*}{ B } & T1 & $0.51 \pm 0.005$ & $0.56 \pm 0.01$ & $0.57 \pm 0.01$ & $0.66 \pm 0.05$ & $0.88 \pm 0.009$ & $0.88 \pm 0.009$ & $0.88 \pm 0.009$ & $0.001^{*}$ \\
\hline & T2 & $0.61 \pm 0.000$ & $0.64 \pm 0.0$ & $0.77 \pm 0.01$ & $0.93 \pm 0.003$ & $0.95 \pm 0.005$ & $0.95 \pm 0.005$ & $0.95 \pm 0.005$ & $0.003^{*}$ \\
\hline \multirow{2}{*}{ C } & T1 & $0.61 \pm 0.006$ & $0.68 \pm 0.004$ & $0.74 \pm 0.004$ & $0.87 \pm 0.004$ & $0.887 \pm 0.01$ & $0.887 \pm 0.01$ & $0.887 \pm 0.01$ & $0.002^{*}$ \\
\hline & T2 & $0.63 \pm 0.007$ & $0.76 \pm 0.007$ & $0.77 \pm 0.01$ & $0.93 \pm 0.005$ & $0.95 \pm 0.04$ & $0.95 \pm 0.04$ & $0.95 \pm 0.04$ & $0.004^{*}$ \\
\hline \multirow{2}{*}{ D } & T1 & $0.54 \pm 0.011$ & $0.71 \pm 0.001$ & $0.74 \pm 0.009$ & $0.81 \pm 0.003$ & $0.90 \pm 0.001$ & $0.90 \pm 0.001$ & $0.90 \pm 0.001$ & $0.005^{*}$ \\
\hline & T2 & $0.62 \pm 0.007$ & $0.75 \pm 0.004$ & $0.76 \pm 0.02$ & $0.93 \pm 0.009$ & $0.94 \pm 0.006$ & $0.94 \pm 0.006$ & $0.94 \pm 0.006$ & $0.001^{*}$ \\
\hline
\end{tabular}

All values are means of triplicate determinations \pm standard deviation (SD), Sample A-Mentha piperita, $T_{1}-$ Hot Air Oven Drying, $T_{2}-$ Freeze Drying Sample B-Zingiber officinale, Sample C-Daucus carota and Sample D-Beta vulgaris filtrate impregnated coconut based snack, Rows followed by different alphabets are *Significantly different $(p \leq 0.05)$, NS- Not Significant by LSD

Table 6: Coefficient of rehydration of the ready-to-eat coconut based snack.

and freeze drier which resulted in quick reaction and moreover within a minimum duration, where maximum water absorption took place at $20^{\text {th }}$ min of rehydration process according to the concept of Maskan [42].

\section{Conclusion}

The filtrate of functional ingredients with sugar infusion was considered as a good impregnating solution used to carry out OD of coconut slices. In fact, the use of functional ingredients contributed a high nutritive value product with antioxidant properties. On concerning this, the functional ingredients could be endorsed for the preservation of many fruits and vegetables using OD technology. The rate of various OD parameters such as mass transfer kinetics, TSS, SAR, acidity and rehydration properties was in reliant with time and temperature and also diffusion mechanism. The diffusion lead to the process of leaching of natural solutes occurred from the coconut slices in to the solution which is not negligible quantitatively, but contributed towards the nutritional and organoleptic traits of the coconut slices and functional filtrates. OD process not only leads to change in composition of tissues but resulted in modification of cell structure, which was analyzed using texture analyzer. OD was noted as a good method to valorize coconut slices, suggesting utilization of filtrates of functional ingredients in formulations of nutritious healthy snack food items.

\section{Acknowledgement}

The authors express our gratitude towards University Grants Commission, New Delhi for the award of 'Junior Research Fellowship' for meritorious students.

\section{References}

1. Torreggiani D (1993) Osmotic dehydration in fruit and vegetable processing. Food Research International 26: 59-68.

2. Pathak RK, Ram RA (2002) Approaches for green good production in horticulture. In Souvenir, National Seminar-cum-workshop on Hi-Tech Horticulture and Precision Farming 33-35.

3. Lombard GE, Oliveira JC, Fito P, Andrés A (2008) Osmotic dehydration of pineapple as a pre-treatment for further drying. Journal of Food Engineering 85 : 277-284

4. Kabara JJ (1984) Antimicrobial agents derived from fatty acids. Journal of the American Oil Chemists Society 61: 397-403.

5. Welti J, Palou E, Lopez-Malo A, Balseira A (1995) Osmotic concentration Drying of mango slices. Drying Technology 13: 405-416.

6. Taiwo KA, Angersbach A, Knorr D (2002) Influence of high intensity electric field pulses and osmotic dehydration on the rehydration characteristics of apple slices at different temperatures. Journal of Food Engineering 52: 185-192.

7. Crozier A, Lean MEJ, McDonald MS, Black C (1997) Quantitative analysis of flavonoid content of commercial tomatoes, onions, lettuce, and celery. Journal of Agricultural and Food Chemistry 45: 590-595.

8. Lerici CR, Pinnavaia G, Rosa MD, Bartolucci L (1985) Osmotic dehydration of fruit: Influence of osmotic agents on drying behavior and product quality. Journal of Food science 50: 1217-1219.

9. Demirel D, Turhan M (2003) Air-drying behavior of dwarf cavendish and gros michel banana slices. Journal of Food Engineering 59: 1-11.

10. AOAC (1990) Official Method of Analysis of the Official Analytical Chemist 25th Ed. Virgin.

11. Evans L (2007) Senior scientific associate expert committee (DSN) Dietary Supplements: Non-botanicals, USP27-NF22, Pharmacopeia Forum.

12. Raoult-Wack AL (1994) Recent advances in the osmotic dehydration of foods. Trends in Food Science \& Technology 5: 255-260.

13. Chiralt A, Fito $P(2003)$ Transport mechanisms in osmotic dehydration. The role of the structure. Food Science and Technology International 9: 179-186.

14. Ozen BF, Dock LL, Ozdemir M, Floros JD (2002) Processing factors affecting the osmotic dehydration of diced green peppers. International Journal of Food Science and Technology 37: 497-502.

15. Ranganna S (1986) Vitamins: In Hand book of Analysis and quality contro for fruit and vegetable products. (2ndedn), Tata McGraw Hill publishing Co.Itd, New Delhi.

16. Rebecca OPS, Boyce AN, Chandran S (2010) Pigment identification and antioxidant properties of red dragon fruit (Hylocereus polyrhizus). African Journal of Biotechnology 9: 1450-1454.

17. Mazza G (1983) Dehydration of carrots. International Journal of Food Science and Technology 18: 113-123

18. Lima AWO, Cal-Vidal J (1983) Hygroscopic behaviour of freeze dried bananas. International Journal of Food Science \& Technology 18: 687-696.

19. Nieto A, Salvatori D, Castro MA, Alzamora SM (1998) Air drying behaviour of apples as affected by blanching and glucose impregnation. Journal of Food Engineering 36: 63-79.

20. Kaymak-Ertekin F (2002) Drying and rehydrating kinetics of green and red peppers. Journal of Food Science 67: 168-175.

21. Nindo Cl, Sun T, Wang SW, Tang J, Powers JR (2003) Evaluation of drying technologies for retention of physical quality and antioxidants in asparagus (Asparagus officinalis L.). LWT-Food Science and Technology 36: 507-516.

22. Lewicki PP (1998) Some remarks on rehydration of dried foods. Journal of Food Engineering 36: 81-87.

23. Dahiya S, Dhawan SS (2003) Effect of drying methods on nutritional composition of dehydrated aonla fruit (Emblica officinalis, Garten) during storage. Plant Foods for Human Nutrition 58: 1-9. 
Citation: Sivasakthi M, Sangeetha N (2015) A Comparative Study of the Physico-Chemical Characteristics of the Ready-to Eat Coconut Based Snack. J Food Process Technol 6: 489. doi:10.4172/2157-7110.1000489

Page 10 of 10

24. Imran M, Khan H, Shah M, Khan R, Khan F (2010) Chemical composition and antioxidant activity of certain Morus species. Journal of Zhejiang University Science B 11: 973-980.

25. Spiess, WEL, Behsnilian D (1998) Osmotic treatments in food processing. Current State and Future Needs 98: 47056.

26. Azuara E, Gutiérrez Cl, Gutierrez GF (2002) Osmotic dehydration of apples by immersion in concentrated sucrose/maltodextrin solutions. Journal of Food Processing and Preservation 26: 295-306.

27. Delgado AE, Rubiolo AC (2005) Microstructural changes in strawberry after freezing and thawing processes. LWT- Food Science and Technology 38: 135-142.

28. Fathi M, Mohebbi M, Razavi SMA (2011) Effect of osmotic dehydration and air drying on physicochemical properties of dried kiwifruit and modeling of dehydration process using neural network and genetic algorithm. Journal of Food and Bioprocess Technology 4: 1519-1526.

29. Krokida M, Maroulis ZB (2000) Quality changes during drying of food materials. In drying technology in agricultural and food sciences. AS Mujumdar (Edn), Enfield Science Publishers.

30. Larrauri JA, Sánchez-Moren C, Saura-Calixto F (1998) Effect of temperature on the free radical scavenging capacity of extracts from red and white grape pomace peels. Journal of agricultural and food chemistry 46: 2694-2697.

31. Krokida MK, Oreopoulou V, Maroulis, ZB (2000) Water loss and oil uptake as a function of frying time. Journal of Food Engineering 44: 39-46.

32. Waliszewski K, Cortes HD, Pardio VT, Garcia MA (1999) Color parameter changes in banana slices during osmotic dehydration. Drying Technology 17 : 955-960.

33. Bekele Y, Ramaswamy H (2010) Going beyond conventional osmotic dehydration for quality advantage and energy savings. Engineering Journal and Science Technology (EJAST) 1: 1-15

34. Rastogi NK, Raghavarao KSMS (2004) Mass transfer during osmotic dehydration of pineapple: considering Fickian diffusion in cubical configuration. LWT-Food Science and Technology 37: 43-47.

35. Bchir B, Besbes S, Karoui R, Paquot M, Attia H, et al. (2012) Osmotic dehydration kinetics of pomegranate seeds using date juice as an immersion solution base. Food and Bioprocess Technology 5: 999-1009.

36. Pavlov A, Kovatcheva P, Georgiev V, Koleva I, llieva M (2002) Bio synthesis and radical scavenging activity of betalains during the cultivation of red beet (Beta vulgaris) hairy root cultures. Journal of Biotechnology 57: 640-644.

37. Olajide PS, Samuel OA, Sanni LO, Bamiro FO (2010) Optimization of pre-fry drying of yam slices using response surface methodology. Journal of Food Process Engineering 33: 626-648.

38. Lakshmi B, Vimala $\vee(2000)$ Nutritive value of dehydrated green leafy vegetable powders. Journal of Food Science and Technology 37: 465-471.

39. Santacruz-Vazquez V, Santacruz V, Azquez C, Welti-Chanes J, FarreraRebollo, et al. (2008) Effects of air drying on the shrinkage, surface temperatures and structural features of apples slabs by means of fractal analysis. Revista Mexicana de Ingenier'ıQu'ımica 7: 55-63.

40. Kowalska H, Lenart A, Leszczyk D (2008) The effect of blanching and freezing on osmotic dehydration of pumpkin. Journal of Food Engineering 86: 30-38.

41. Tunde-Akintunde TY (2011) Mathematical modeling of sun and solar drying of chilli pepper. Renewable Energy 36: 2139-2145.

42. Maskan M (2001) Drying, shrinkage and rehydration characteristics of kiwifruits during hot air and microwave drying. Journal of Food Engineering 48: 177-182. 